Artículo

\title{
La biofertilización y nutrición en el desarrollo de plántulas de chile serrano
}

I. Cabanzo-Atilano ${ }^{1}$

M. N. Rodríguez-Mendoza ${ }^{1 \S}$

J. L. García-Cué

J. J. Almaraz-Suárez ${ }^{1}$

Ma. del Carmen Gutiérrez-Castorena ${ }^{1}$

${ }^{1}$ Postgrado en Edafología-Colegio de Postgraduados-Campus Montecillo. Carretera México-Texcoco km 36.5, Montecillo, Texcoco, Estado de México, México. CP. 56230. (ivan.cabanzo@gmail.com; jalmaraz@colpos.mx; castor@colpos.mx). ${ }^{2}$ Postgrado de Estadística-Colegio de Postgraduados-Campus Montecillo. Carretera México-Texcoco km 36.5, Montecillo, Texcoco, Estado de México, México. CP. 56230. (jlgcue@colpos.mx).

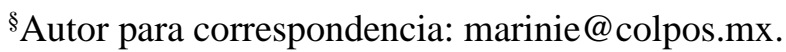

\section{Resumen}

La producción de plántulas de calidad es primordial para que durante el trasplante se propicie un crecimiento óptimo y buenos rendimientos del cultivo; por ello, el objetivo de la presente investigación fue determinar el efecto de bacterias promotoras de crecimiento vegetal y el manejo de la nutrición en la fisiología y crecimiento de plántulas de chile serrano. En condiciones de invernadero se llevó a cabo un experimento, con chile serrano var. Tampiqueña 74, bajo un diseño completamente al azar con arreglo factorial de $2 \times 2 \times 2$. Los factores fueron: inoculación (con o sin Pseudomonas tolaasii), sustrato (con y sin esterilizar), y solución nutritiva (Steiner y té de vermicompost) con un total de ocho tratamientos con cuatro repeticiones cada uno. Los resultados indican que el efecto de $P$. tolaasii es altamente significativo en sustrato no esterilizado y con solución Steiner, donde las plántulas presentaron mayor altura, diámetro del tallo, área foliar, y la biomasa seca de parte aérea. Además, aumentó la concentración de $\mathrm{NO}_{3}$ en savia. Con el té de vermicompost la inoculación solo impactó en la longitud y volumen radical; mientras que con la solución Steiner únicamente tuvo efecto en el contenido nutritivo de $\mathrm{N} \mathrm{y} \mathrm{K}^{+}$e índices de crecimiento. La inoculación de $P$. tolaasii en plántulas de chile serrano favorece la fisiología y concentración nutritiva siempre y cuando no se esterilice el sustrato. El menor efecto sobre las plántulas ocurre si sólo se suministra té de vermicompost.

Palabras clave: almácigos, nutrición vegetal, rizobacterias.

Recibido: febrero de 2020

Aceptado: abril de 2020 


\section{Introducción}

La calidad de las plántulas es la combinación de características como la altura, diámetro de tallo, longitud de raíz y concentración nutrimental (Araméndiz-Tatis et al., 2013), número de hojas y área foliar (Vidigal et al., 2011), que repercuten en el vigor de éstas. Un buen desarrollo, libre de plagas y enfermedades permite mayor adaptabilidad al trasplante, con alta capacidad de absorción de agua y nutrientes (Salusso et al., 2015). Sarduy et al. (2016) mencionaron que producir plántulas de chile (Capsicum annuum L.) de calidad desde almacigo, garantiza una excelente producción bajo invernadero.

La generación de plántulas sanas y vigorosas es primordial para después del trasplante obtener un crecimiento óptimo y rendimientos altos, tanto en el campo como en invernadero (Souri y Sooraki, 2019) y en donde influyen factores como el sustrato, la solución nutritiva e inoculantes. Los sustratos son importantes para la producción de plántula ya que inciden directamente en la fisiología y calidad de éstas (Richmond, 2010; López-Baltazar et al., 2013).

Aunado a la nutrición que desempeña un papel vital en la germinación, fisiología y calidad de las plántulas (Marschner, 2012; Santos et al., 2014) y es posible controlar su crecimiento manipulando la concentraciones y proporciones de las soluciones nutritivas (Souri y Sooraki, 2019). El té de vermicompost es definido por Tortosa (2017), como un líquido acuoso orgánico, obtenido de vermicompost maduro donde se encuentran y reproducen microorganismos con características benéficas y protectoras para las plantas, además de poseer propiedades nutritivas contiene suficientes nutrientes para el crecimiento y desarrollo de las especies hortícolas, por ello es recomendado como otra alternativa para la producción convencional o hidropónica (González et al., 2013).

La inoculación de rizobacterias promotoras de crecimiento vegetal (RPCV) que puede ser una sola cepa o en consorcio (Ahemad y Khan, 2012), influyen en los cambios bioquímicos, físiológicos y morfológicos de las plantas (Bhattacharyya y Jha, 2012), a través de mecanismos como la producción de fitohormonas (Glick, 2012) y participan en el antagonismo contra microorganismos patógenos (Carreón et al., 2013). Su función como biofertilizantes favorece el estado nutricional de los cultivos (Mohamed et al., 2019); a través, de la fijación biológica y disponibilidad de nitrógeno y solubilización de fósforo (Aloo et al., 2019; Syed y Tollamadugu, 2019).

El uso de RPCV fortalece los procesos bioquímicos y fisiológicos de las plántulas, lo que genera mayor resistencia a estrés de post trasplante (Sapre et al., 2018). El género Pseudomonas engloba numerosos nichos ecológicos, donde algunas son promotoras del crecimiento vegetal (RiverosRosas et al., 2019), funcionan como biofertilizante y pueden ser útiles en el control biológico de enfermedades (Widnyana y Javandira, 2016).

De $P$. tolaasii se tienen pocos reportes que indiquen su potencia como RPCV en chile, esta cepa aislada y caracterizada por propiedades bioquímicas específicas y promotora de crecimiento (Quiroz-Sarmiento et al., 2019), está siendo evaluada en varios cultivos. La hipótesis que se plantea en el presente estudio es que la inoculación de $P$. tolaasii combinada con té de vermicompost favorece el desarrollo agronómico y nutritivo de plántulas de chile serrano. 
El objetivo de la presente investigación fue cuantificar el efecto de la inoculación de Pseudomonas tolaasii en la fisiología y desarrollo de plántulas de chile serrano (Capsicum annuum L.) utilizando diferentes soluciones nutritivas.

\section{Materiales y métodos}

\section{Materiales utilizados}

En un invernadero de tipo túnel del Área de Nutrición Vegetal del Colegio de Postgraduados, de mayo a julio de 2018 se instaló el experimento. Se utilizaron semillas de chile serrano (Capsicum annuиm L.) variedad Tampiqueña 74 (Caloro $\left.{ }^{\circledR}\right)$, con tasa de germinación de $85 \%$. Se utilizaron charolas de germinación de polietileno flexible negras de 25 cavidades redondas $\left(85.6 \mathrm{~cm}^{3}\right.$ cavidad $^{-1}$ ), desinfectadas con cloro a una concentración de 200 ppm y lavadas con agua.

Se sembraron dos semillas por cavidad para garantizar la germinación. El sustrato fue a base de una mezcla de peat moss $\left(\right.$ Premier $\left.^{\circledR}\right)$, perlita $\left(\right.$ Agrolita $\left.^{\circledR}\right)$ y vermiculita $\left(\right.$ Termita $\left.^{\circledR}\right)$ con relación de 1:1:1 (v/v/v), la mitad de la mezcla preparada se esterilizó con una olla de presión $\left(1.3 \mathrm{~kg} \mathrm{~cm}^{-2}\right)$, la otra mitad se utilizó sin esterilización de acuerdo con los tratamientos establecidos.

\section{Establecimiento y diseño experimental}

El experimento se estableció bajo un diseño completamente al azar (DCA) con arreglo factorial de $2 \times 2 \times 2$, donde los factores de estudio fueron: con o sin inoculación con $P$. tolaasii $(\mathrm{P})$, el sustrato esterilizado (SE) y sustrato no esterilizado (SNE) y la solución nutritiva con Steiner (St) y té de vermicompost (Te).

Se evaluaron un total de ocho tratamientos con cuatro repeticiones cada uno. La unidad experimental fue una charola de almácigo con 25 plántulas de chile serrano, las cuales se regaron con agua esterilizada dos a tres veces por día. La emergencia de plántulas se presentó a partir de los 12 días y se ralearon cuatro días después dejando una plántula por cavidad.

\section{Material microbiológico}

Como inóculo se utilizó la cepa bacteriana P61 de $P$. tolaasii, perteneciente a la colección del Laboratorio de Microbiología de Suelos del Postgrado de Edafología. La inoculación de la bacteria se realizó a los seis días después de la emergencia, aplicando $1 \mathrm{~mL}$ de inóculo con una concentración de $1 \times 10^{9} \mathrm{UFC} \mathrm{mL}^{-1}$ en la base de cada plántula.

\section{Solución nutritiva}

Al tercer día después de la inoculación se inició la nutrición de las plántulas, utilizando la solución nutritiva universal Steiner al 25\% (Steiner,1984). Como segunda fuente de nutrición se elaboró el té de vermicompost preparado de acuerdo con el método de González-Solano et al. (2014). Ambas soluciones se ajustaron a pH de 5.5 y 24 días después se incrementó su concentración a 50\% en ambas soluciones hasta el trasplante. La concentración se calculó con base en la conductividad eléctrica de la solución de Steiner. 


\section{Variables evaluadas}

A los 56 días después de la siembra se realizó una cosecha destructiva. Las variables evaluadas fueron: diámetro de tallo $(\mathrm{mm})$, altura de plántula $(\mathrm{cm})$, número de hojas, área foliar $\left(\mathrm{cm}^{2}\right)$ con un equipo medidor de área LI-COR ${ }^{\circledR}$, la longitud $(\mathrm{cm})$ y volumen radical $\left(\mathrm{cm}^{3}\right)$ se determinaron con el método de desplazamiento de agua con probeta de $25 \mathrm{~mL}$.

Además, se cuantificó el $\mathrm{NO}_{3}{ }^{-}, \mathrm{K}^{+}$y $\mathrm{Ca}^{2+}$ en extracto celular del peciolo (savia) con ionómetros Laquatwin $^{\circledR}$. Las plántulas se secaron en el horno a $55^{\circ} \mathrm{C}$ durante $72 \mathrm{~h}$ y se pesaron para obtener la biomasa seca de la parte aérea y radical. Con los valores obtenidos se calcularon los índices de crecimiento según Hunt (2017) (Cuadro 1).

Cuadro 1. Índices de crecimiento según la descripción de Hunt (2017).

\begin{tabular}{ccc}
\hline Indicador de crecimiento & Fórmula & Unidades \\
\hline Relación de área foliar & $\mathrm{RAF}=\mathrm{AF} / \mathrm{BS}$ & $\left(\mathrm{cm}^{2} \mathrm{~g}^{-1} \mathrm{de} \mathrm{BS}\right)$ \\
Área foliar específica & $\mathrm{AFE}=\mathrm{AF} / \mathrm{BSAF}$ & $\left(\mathrm{cm}^{2} \mathrm{~g}^{-1}\right)$ \\
\hline
\end{tabular}

$\mathrm{AF}=$ área foliar de la planta; $\mathrm{BS}=$ biomasa seca total; $\mathrm{BSA}=$ biomasa seca del área foliar.

\section{Análisis nutrimental}

En el material vegetal seco se determinó el nitrógeno (N) total por el método microKjeldahl, fósforo (P) y potasio $(\mathrm{K})$ por medio de digestión húmeda y espectroscopia de emisión atómica de inducción por plasma utilizando la metodología propuesta por Alcántar y Sandoval (1999).

\section{Análisis estadístico}

Los datos obtenidos de las variables evaluadas fueron sometidos a la prueba de normalidad de Shapiro-Wilk $(\alpha=0.05)$ y la prueba de Levene para homogeneidad de varianza. A las variables de longitud radical, biomasa seca radical, biomasa seca de la parte aérea, AFE, $\mathrm{RAF}, \mathrm{NO}_{3}, \mathrm{~K}^{+}$, $\mathrm{Ca}^{2+}$ en extracto celular y concentración nutrimental $(\mathrm{N}, \mathrm{P}, \mathrm{K})$, que cumplieron con ambas pruebas se les aplicaron análisis de varianza (Anova) y la prueba de comparación de medias de Tukey $(\alpha=0.05)$.

Las variables altura, diámetro de tallo, número de hojas y área foliar que no cumplieron con las pruebas de homogeneidad de varianza o normalidad, fueron transformadas a logaritmo natural (ln) hasta observar normalidad y homocedasticidad, posteriormente se calculó el Anova y la prueba de comparación de medias de Tukey $(\alpha=0.05)$.

Los datos del volumen radical, biomasa seca de hoja no cumplieron con ambas pruebas, por lo que se hizo un análisis no paramétrico de Kruskal-Wallis y la sumatoria de rangos de Wilcoxon, de acuerdo con la metodología de Siegel (2015). Para todos los casos se trabajó con el programa estadístico Statistical Analysis System (SAS) Versión 9.4 (SAS, 2014). 


\section{Resultados y discusión}

En el experimento evaluado, los análisis de varianza de las variables agronómicas y las de análisis nutrimental (Cuadro 2), fueron altamente significativas $(p \leq 0.001)$ entre tratamientos y los valores bajos del coeficiente de variación dieron confiabilidad de los análisis.

Cuadro 2. Significancia estadística de tratamientos $(p<0.05)$ en las variables agronómicas y análisis nutrimental de plántulas de chile serrano inoculadas y diferente solución nutritiva.

\begin{tabular}{cccccccccccc}
\hline FV & LR & BSR & BSA & AFE & RAF & $\mathrm{NO}_{3}$ & $\mathrm{~K}$ & $\mathrm{Ca}$ & $\mathrm{N}$ & $\mathrm{P}$ & $\mathrm{K}$ \\
\hline TRAT & $* *$ & $* *$ & $* *$ & $* *$ & $* *$ & $* *$ & $* *$ & $* *$ & $* *$ & $*$ & $* *$ \\
$\mathrm{CV}(\%)$ & 19.38 & 46.86 & 27.75 & 14.52 & 15.5 & 17.97 & 8.73 & 22.72 & 9.98 & 9.02 & 37.85 \\
$\mathrm{R}^{2}$ & 0.167 & 0.106 & 0.483 & 0.261 & 0.275 & 0.838 & 0.861 & 0.808 & 0.729 & 0.951 & 0.584 \\
MEDIA & 16.04 & 0.15 & 0.25 & 200.87 & 151.38 & 4278.13 & 367.8 & 40.56 & 45654.8 & 2911.1 & 23074 \\
\hline
\end{tabular}

$\mathrm{FV}=$ fuente de variación; TRAT $=$ tratamiento; $\mathrm{CV}=$ coeficiente de variación; $\mathrm{LR}=$ longitud radical; $\mathrm{BSR}=$ biomasa seca radical; $\mathrm{BSA}=$ biomasa seca total aérea; $\mathrm{AFE}=$ área foliar específica; $\mathrm{RAF}=$ relación de área foliar; $\mathrm{NO}_{3}=$ nitratos en savia; $\mathrm{K}=$ potasio en savia; $\mathrm{Ca}=$ calcio en savia; $\mathrm{N}=$ nitrógeno en plántula; $\mathrm{P}=$ fósforo en plántula; $\mathrm{K}=$ potasio en plántula; ${ }^{*}=$ significativo $(p>0.001-p \leq 0.05) ;{ }^{* *}=$ altamente significativo $(p \leq 0.001)$.

\section{Variables agronómicas}

La longitud y biomasa seca radical, la biomasa seca de la parte aérea, AFE y RAF presentaron diferencias estadísticas entre los tratamientos según Tukey $(p<0.05)$ (Figura 1). Las plántulas que se desarrollaron en sustrato no estéril tuvieron un ligero incremento en la longitud de raíz, a diferencia de las que crecieron en sustrato estéril, sin embargo, en biomasa seca de raíz no hay diferencias entre estas.

En relación con la fuente de nutrición, cuando se aplica té como solución, hay incremento en la longitud y biomasa seca, aunque la prueba de Tukey indica en algunos casos que no hay diferencias (Figura 1a). Es interesante ver que la altura y biomasa de raíz en plántulas sin sustrato estéril y con té presentan los valores más altos de longitud y biomasa seca radical.

Respuestas favorables a fuentes orgánicas han sido registradas por David-Santoya et al. (2018) para chile habanero (Capsicum chinense Jacquin) y con inoculantes para incrementar la longitud radical de C. annuum con Rhizobium etli, y con Trichoderma viride por Vazallo et al. (2013). Una mayor longitud radical en las plántulas permite que pueda sobrellevar de manera eficiente el trasplante y lograr una rápida adaptación y absorción de agua y nutrientes (Vazallo et al., 2013).

En el análisis de la parte aérea, la Figura 1b muestra que los tratamientos PSNESt y PSESt registraron la mayor biomasa seca (tallo + hojas) de las plántulas, alcanzando $0.34 \mathrm{~g} \mathrm{y} 0.33 \mathrm{~g}$ planta $^{-1}$, respectivamente. Esto significa que en la parte aérea de la plántula hay una respuesta a la inoculación de Pseudomonas tolaasii y a la aplicación de solución nutritiva Steiner sin importar la esterilización de sustrato. 

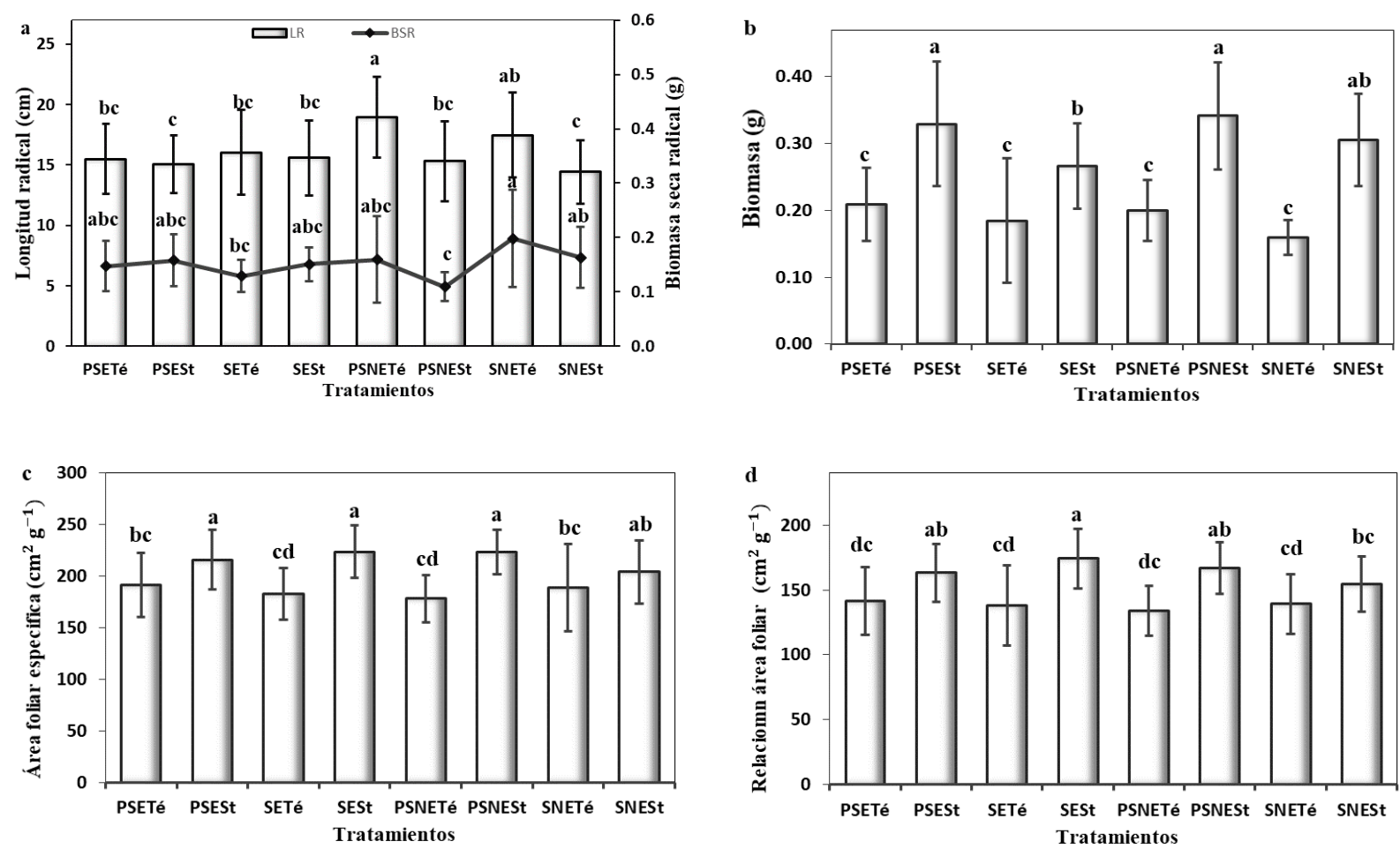

Figura 1. a) Longitud radical y biomasa seca radical; b) biomasa seca de la parte aérea; c) área foliar específica; y d) relación de área foliar de plántulas de chile serrano inoculada con p. tolaasii y diferente solución nutritiva. Barras con diferente letra, son estadísticamente diferentes de acuerdo con la prueba de medias de Tukey $(p<0.05)$. $\mathrm{P}=$ Pseudomonas tolaasii; $\mathrm{S}=$ sustrato; $\mathrm{E}=$ esterilizado; $\mathrm{NE}=$ no esterilizado; $\mathrm{St}=\mathrm{Steiner} ; \mathrm{Te}=$ té de vermicompost.

Esto se atribuye a que, $P$. tolaasii benefició la absorción de nutrientes disponibles incorporadas con solución Steiner (Angulo-Castro et al., 2018) y a la mejora en el desarrollo de la raíz cuando hay inoculación con las rizobacterias (Natarajan et al., 2012). La inoculación de $P$. tolassi a plantas de fresa, favorece el desarrollo de la planta (incremento en área foliar y peso fresco de follaje), aunque no se refleja en incremento en la producción de fruto (Ortiz et al., 2016).

La biomasa de la parte aérea de las plántulas crecidas en sustrato no estéril (Figura 1b) y regadas con solución Steiner fue muy similar a las inoculadas con Pseudomonas; sin embargo, la longitud de raíz y biomasa fueron reducidas (Figura 1a) y esto tiene mucho que ver con la adaptación de las plántulas al trasplante. En los índices de AFE (Figura 1c) y RAF (Figura 1d), la incorporación de solución Steiner sin la inoculación incrementaron los valores, en sustratos esterilizados.

Resultados similares han sido registrados en plántulas de pimiento (Luna et al., 2013) y en chile jalapeño (Angulo-Castro et al., 2018), cuando se inocularon con Pseudomonas. Amanullah et al., 2007, indican que los valores altos de AFE, representan mayor espesor de la hoja y mejor balance entre la capacidad potencial de la fotosíntesis y el costo de respiración.

Estos valores se alcanzaron en las plántulas donde hubo un suficiente suministro de nutrientes inorgánicos (St), lo que genera mayor vigor de la planta, determinado por la RAF, así como mayor grosor de hoja regulado por la AFE (Hunt, 2017), índice que permite explicar hasta 80\% de la variación en las tasas de crecimiento (Villar et al., 2004). 
En la Figura 2a se muestra las medias de las variables de altura de plántula y diámetro de tallo, donde la inoculación generó mayor altura (20\% más) y diámetro de tallo (entre 13 y $5 \%$ más) entre los tratamientos PSNESt y PSESt con respecto a sus testigos (SNESt y SESt). La prueba de Tukey muestra diferencias altamente significativas entre estos dos tratamientos y los otros. Resultados similares obtuvieron Luna et al. (2013), con un incremento significativo de altura y diámetro de tallo de plántulas de pimiento al inocular Bacillus subtilis hasta $37 \%$, en comparación con el testigo.
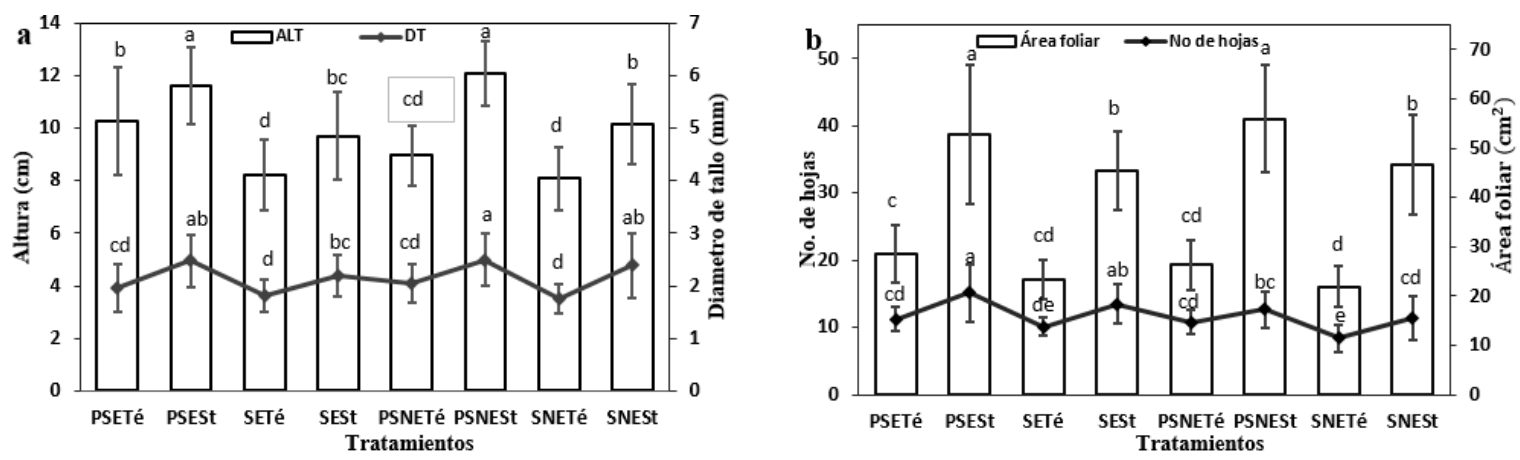

Figura 2. a) altura de plántula y diámetro de tallo; y b) número de hojas y área foliar de plántulas de chile serrano inoculadas y diferente solución nutritiva. $\mathrm{P}=$ Pseudomonas tolaasii; $\mathrm{S}=$ sustrato; $\mathrm{E}=$ esterilizado; $\mathrm{NE}=$ no esterilizado; $\mathrm{St}=\mathrm{Steiner} ; \mathrm{Te}=$ té de vermicompost.

El ácido indolacético (AIA) producido por la cepa inoculada es la principal fitohormona que induce el crecimiento de las plantas, al aumentar la división celular y la diferenciación de los tejidos (Bhattacharyya y Jha, 2012; Glick, 2012). En el caso de chile poblano el incremento en crecimiento fue de $35 \%$ con respecto al testigo por el efecto de la inoculación con bacterias promotoras de crecimiento entre ellas P. tolassi (Quiroz-Sarmiento et al., 2019).

En el número de hojas y área foliar por plántula, el tratamiento inoculado con $P$. tolaasii y regadas con solución nutritiva Steiner en sustrato estéril (PSESt) fue el que registró mayor número de hojas, hasta $12 \%$ más que el testigo (SESt), tal y como se muestra en la Figura 2b. En contraste, para la variable área foliar, se observó la mayor superficie foliar (hasta 20\% más que el testigo), con el tratamiento PSNESt. Los resultados de esta variable indican que la inoculación y la solución nutritiva de Steiner al 25\% suministran los nutrimentos balanceados que se reflejan en el incremento del número de hojas en todas las plántulas que fueron regadas con Steiner. Ya que posiblemente las rizobacterias, proporcionan beneficios para el crecimiento a las plantas cuando se agregan cantidades bajas de fertilizante químico al suelo que no inhiban el crecimiento como lo establecen Bhattacharyya y Jha (2012); Glick (2012).

Se encontraron diferencias estadísticamente significativas en el volumen radical de acuerdo con la prueba de Kruskal-Wallis, siendo el tratamiento PSNETé el que registro mayor volumen con un rango promedio de Wilcoxon de 180.18 (datos no mostrados), mientras que la mayor biomasa seca de hoja se registró con el tratamiento PSNESt, con un rango promedio de Wilcoxon de 224.75 y el tratamiento PSESt con 216.72. En la Figura 3a se muestra las medias de volumen radical, donde se aprecia que el tratamiento PSNETé presentó $3 \mathrm{~cm}^{3}$, superando $31 \%$ a su testigo (SNESt) y el tratamiento SESt obtuvo $2.2 \mathrm{~cm}^{3}$. 
a)

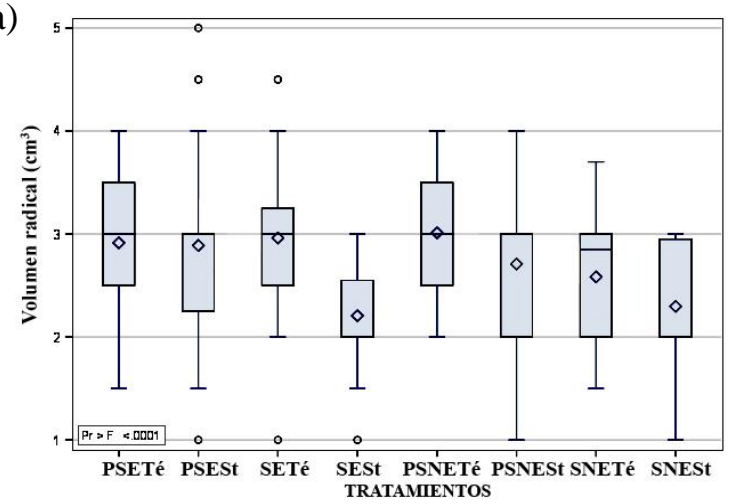

b)

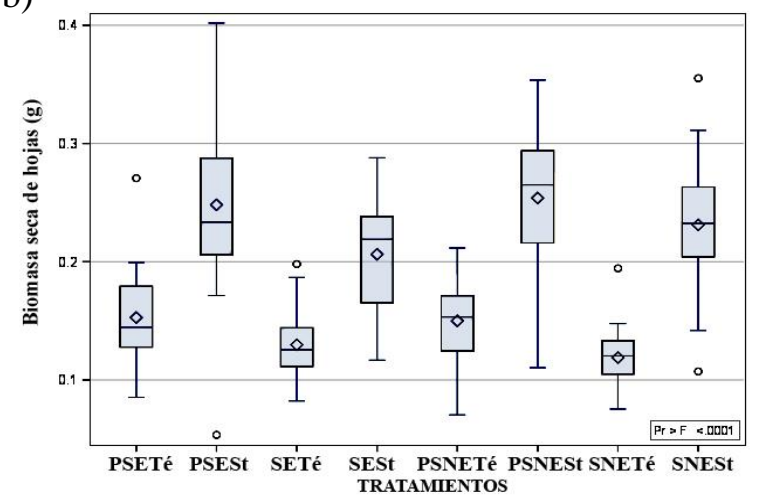

Figura 3. Diagrama de caja contrastando: a) volumen radical; y b) biomasa seca de hojas de plántulas de chile serrano inoculadas y diferente solución nutritiva. $\mathrm{P}=$ Pseudomonas tolaasii; $\mathrm{S}=$ sustrato; $\mathrm{E}=$ esterilizado; $\mathrm{NE}=$ no esterilizado; $\mathrm{St}=\mathrm{Steiner} ; \mathrm{Te}=$ té de vermicompost (análisis no paramétrico de Kruskal-Wallis).

Pérez et al. (2015) obtuvieron incrementos en el volumen radical de hasta $64 \%$ en plántulas de mora (Rubus glaucus L.) inoculadas con Pseudomonas migulae en comparación con el tratamiento sin inoculación. De acuerdo con Amara et al. (2015) Pseudomonas es un género de bacterias capaces de producir y excretar auxinas que son aprovechadas por las plántulas; la más investigada es el ácido indol-3-acético, que es una fitohormona involucrada en la estimulación del crecimiento radical (Glick, 2012).

En la Figura $3 b$ se muestra que la mayor biomasa seca se presentó en los tratamientos PSNESt con una media de $0.253 \mathrm{~g}_{\text {planta }}{ }^{-1}$ y PSESt hasta $0.248 \mathrm{~g}_{\text {planta }}{ }^{-1}$. Parra-Terraza (2016) identificó que el suministro de $\mathrm{NO}_{3}{ }^{-}$en la solución nutritiva, aumentó la biomasa seca de hojas; sin embargo, con la participación de $P$. tolaasii esta variable agronómica es superior entre $20 \%$ y $9 \%$ a sus testigos SNESt y SESt, respectivamente.

\section{Variables nutritivas}

En la concentración de nitratos, potasio y calcio en extracto celular de peciolo de las plántulas de chile, se encontraron diferencias estadísticas $(p<0.05$. En la Figura 4a se observa que las plántulas crecidas en sustrato no estéril, inoculadas y regadas con té, presentaron los valores más bajo de nitratos (1 $450 \mathrm{ppm}$ ). Las plántulas crecidas con sustrato estéril no presentaron diferencias estadísticas significativas entre éstas.

El potasio en el extracto celular (Figura 4b) presento los valores más altos en las plántulas crecidas en sustrato no estéril y únicamente en el testigo estéril (SESt), en cambio el $\mathrm{Ca}^{2+}$, incrementó su contenido en plántulas con sustrato no esterilizado y la inoculación de $P$. tolassii independientemente de la solución nutrimental. Por debajo de estos y estadísticamente igual fue el contenido en las plantas de sustrato no estéril y regadas con sol, Steiner (Figura 4c).

La importancia de conocer la composición química estriba en la calidad del material vegetal de las plántulas, y la reserva de nutrientes minerales, altas concentraciones de nitrógeno y potasio pueden influir sobre el crecimiento y la supervivencia de las plántulas (Villar et al., 2004). Shabayev (2012) informó que la inoculación con P. seudomonas, aumentan la absorción de nutrientes por las plantas, 
el crecimiento, la absorción nutrimental y excreción del sistema radicular asociadas con la secreción de compuestos fenólicos que tiene entre otras cosas la misión de favorecer el micronicho de la rizobacteria.
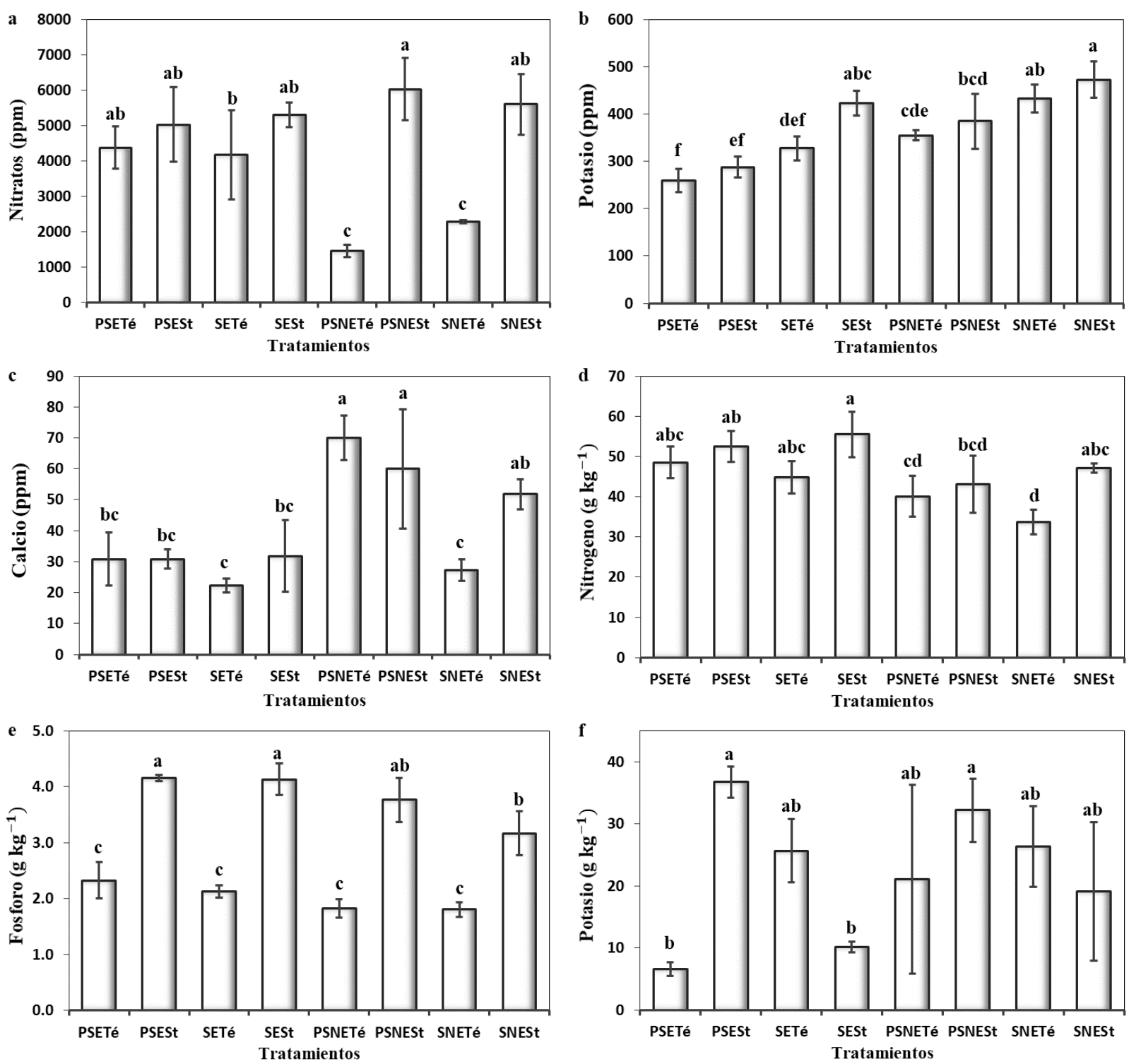

Figura 4. Variables nutritivas: a) nitratos en savia; b) potasio en savia; c) calcio en savia; d) nitrógeno; e) fósforo; y f) potasio en plántulas de chile serrano inoculada y diferente solución nutritiva.Columnas con diferente letra, son estadísticamente diferentes de acuerdo con la prueba de medias de Tukey $(p<0.05) . \mathrm{P}=$ Pseudomonas tolaasii; $\mathrm{S}=$ sustrato; $\mathrm{NE}=$ no esterilizado; $\mathrm{St}=$ Steiner; $\mathrm{Te}=$ té de vermicompost.

Moreno et al. (2018) indicaron que las RPCV participan en la liberación de forma gradual de nutrimentos y contribuyen a la reserva de $\mathrm{N}$ y $\mathrm{P}$ orgánico del suelo, reduciendo las pérdidas de $\mathrm{N}$ por lixiviación y la fijación de $\mathrm{P}$ (ciclo de nutrientes) Además, de suministrar micronutrientes a los cultivos (Glick, 2012). En las Figuras 4d, e, f, se muestra la concentración de N, P y K en biomasa seca de plántulas, con diferencias altamente significativas entre los tratamientos $(p<0.05)$. 
En el tratamiento SESt presentó la mayor concentración de $\mathrm{N}$ con un promedio de $55.5 \mathrm{~g} \mathrm{~kg}^{-1}$; mientras que el tratamiento SNETé registró la concentración más baja (33.6 $\left.\mathrm{g} \mathrm{kg}^{-1}\right)$. Los demás tratamientos fueron estadísticamente similares. En cuanto a la concentración de P, resultaron mejores los tratamientos del sustrato estéril con solución Steiner (PSESt y su testigo SESt), los cuales registraron $4.15 \mathrm{y}^{2} .13 \mathrm{~g} \mathrm{~kg}^{-1}$ respectivamente.

La inoculación combinada con solución nutritiva de Steiner (PSESt y PSNESt), aumentó la concentración de K en biomasa seca, superando en $150 \%$ a $68 \%$ a los testigos (SESt y SNESt), en cambio, el tratamiento PSETé registró la menor concentración de $\mathrm{K}\left(6.56 \mathrm{~g} \mathrm{~kg}^{-1}\right)$, siendo $36 \%$ menor que su testigo (SESt). Jones (2014) indicó que la fertilización con solución Steiner mejoró la calidad de las plántulas, para el trasplante, debido a una mayor disponibilidad de nutrientes.

Mientras que en la presente investigación el suministro de solución Steiner benefició las variables nutritivas en plántulas y algunas variables agronómicas. El equilibrio adecuado y la utilización de iones en la solución nutritiva se logró mediante el uso de sus fórmulas universales de solución nutritiva que mejoran la concentración de nutrientes en la materia vegetal (Steiner 1984).

En el Cuadro 3 se sintetizan las variables en estudio sobre el efecto de la inoculación con Pseudomonas tolaasii que al ser combinada con solución nutritiva de Steiner en sustratos no estériles tuvieron mejores resultados en variables agronómicas como altura, diámetro de tallo, área foliar y biomasa seca aérea, observándose que la combinación de la inoculación con té de vermicompost en sustrato no estéril influye al aumentar la longitud y volumen radical.

Cuadro 3. Respuesta de las plántulas de chile serrano a la inoculación de Pseudomonas tolaasii sobre las variables agronómicas y nutritivas.

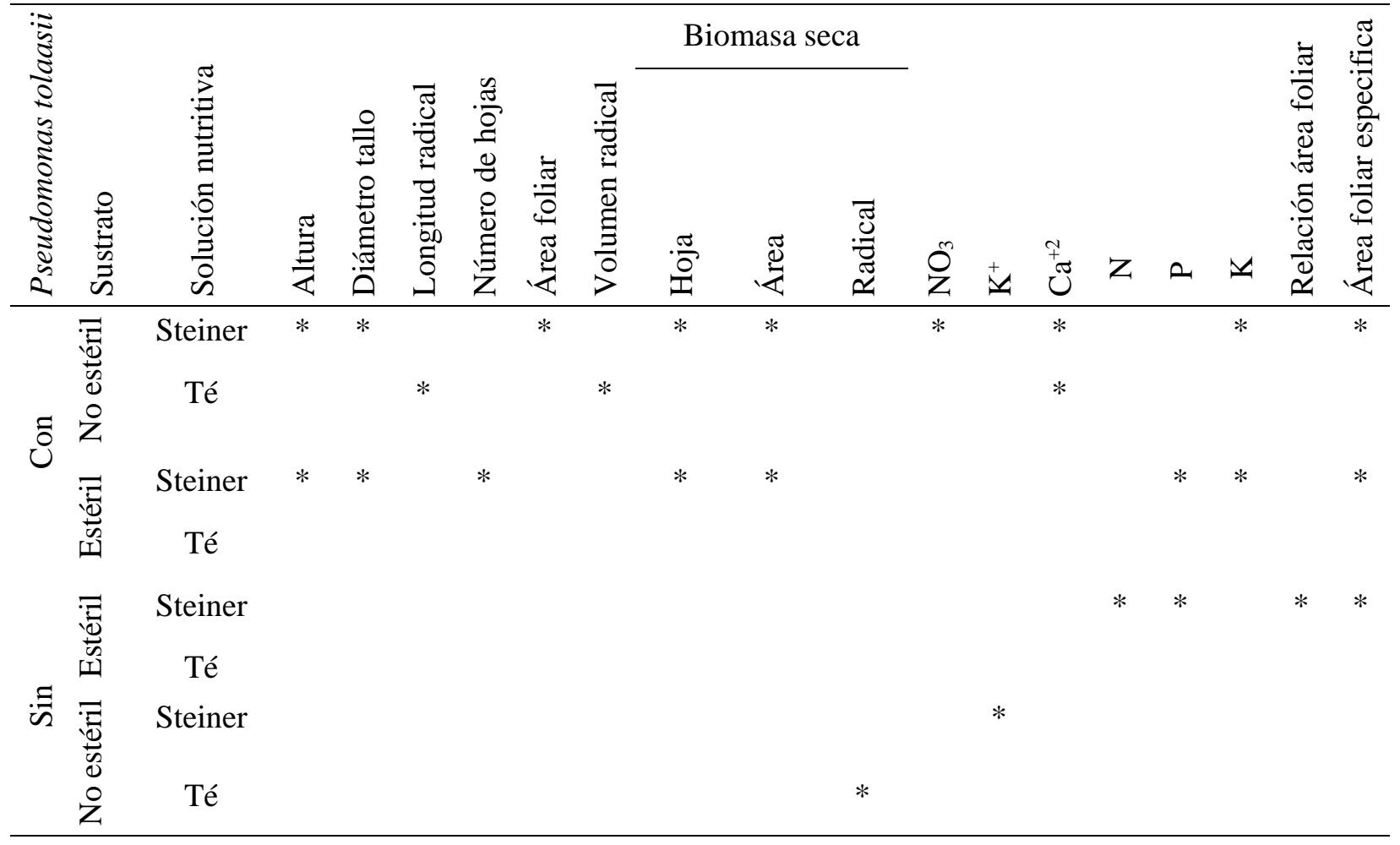

*= mejor respuesta de los factores. 
No así cuando se aplica solo té de vermicompost, ya que no presenta ninguna respuesta positiva, lo que significa que la inoculación de $P$. tolaasii probablemente tiene efectos positivos cuando tiene interacción con otros microrganismos nativos o coinoculados con diferente capacidad promotora (sustrato y té) (Ahemad y Khan, 2012; Rojas et al., 2001).

Sin embargo, cuando solamente se aplica solución Steiner eliminando todos los microrganismos solo se beneficia la concentración nutrimental e influye en los índices de crecimiento debido a que la nutrición aplicada a las plantas puede afectar la estructura de las comunidades bacterianas en la rizosfera (Glick, 2012, Shabayev, 2012). Y es que el proceso de colonización en un paso decisivo en la interacción entre bacteria y planta, esta última secreta exudados ricos en nutrimentos que son utilizados por las bacterias en la sprimeras etapas de reconocimiento (Abaid-Ullah et al., 2015).

La hipótesis que se plantea en el presente estudio es que la inoculación de $P$. tolaasii combinada con té de vermicompost favorece el desarrollo agronómico y nutritivo de plántulas de chile serrano. Por lo tanto, el objetivo de la presente investigación fue cuantificar el efecto de la inoculación de Pseudomonas tolaasii en la fisiología y desarrollo de plántulas de chile serrano (Capsicum annuum L.) utilizando diferentes soluciones nutritivas.

\section{Conclusiones}

La producción de plántulas de calidad de chile serrano se da con la inoculación de Pseudomonas tolaasii y la aplicación de solución Steiner al 25\% como fuente nutrimental. El uso de sustrato no estéril al parecer favorece el desarrollo de la plántula con o sin la inoculación de la bacteria promotora de crecimiento. El té de vermicompost a pesar de ser una fuente de nutrimentos, no son suficientes para la obtención de plántulas bien desarrolladas, a pesar de favorecer el desarrollo de la raíz de éstas.

\section{Literatura citada}

Abaid-Ullah, M. M. N.; Hassan, M.; Jamil, G.; Brader, M. K. N.; Shah, A. and Sessitsch-Hafeez, F. Y. 2015. Plant growth promoting rhizobacteria: an alternate way to improve yield and quality of wheat (Triticum aestivum). Int. J. Agric. Biol. 17 (1):51-60.

Ahemad, M. and Khan, M. S. 2012. Alleviation of fungicide-induced phytotoxicity in greengram [Vigna radiata (L.) Wilczek] using fungicide-tolerant and plant growth promoting Pseudomonas strain. Saudi Journal of Biological Sciences. 19(4),451-459.

Alcántar, G. G. y Sandoval, V. M. 1999. Manual de análisis químico de tejido vegetal. Guía de muestreo, preparación, análisis e interpretación. Publicación especial 10. Sociedad Mexicana de la Ciencia del Suelo A. C. Chapingo, Estado de México. 156 p.

Aloo, B. N.; Makumba, B. A. and Mbega, E. R. 2019. The potential of Bacilli rhizobacteria for sustainable crop production and environmental sustainability. Microbiological Research, 219(1): 26-39.

Amara, U.; Khalid, R. and Hayat, R. 2015. Soil bacteria and phytohormones for sustainable crop production. In bacterial metabolites for sustainable agroecosystem. Springer International Publishing. 87-103 pp. 
Amanullah, H. M. J.; Nawab, K. and Ali, A. 2007. Response of specific leaf area (SLA), leaf area index (LAI) and leaf area ratio (LAR) of maize (Zea mays L.) to plant density, rate and timing of nitrogen application. World Applied Sciences Journal. 2 (3): 235-243.

Angulo-Castro, A.; Ferrera-Cerrato, R.; Alarcón, A.; Almaraz-Suárez, J. J.; Delgadillo-Martínez, J.; Jiménez-Fernández, M. y García-Barradas, O. 2018. Crecimiento y eficiencia fotoquímica del fotosistema ii en plántulas de 2 variedades de Capsicum annuum L. inoculadas con rizobacterias u hongos micorrícicos arbusculares. Revista Argentina de Microbiología. 50 (2):178-188.

Araméndiz-Tatis, H.; Cardona-Ayala, C. y Correa-Álvarez, E. 2013. Efecto de diferentes sustratos en la calidad de plántulas de berenjena (Solanum melongena L.). Revista Colombiana De Ciencias Hortícolas, 7 (1): 55-61.

Bhattacharyya, P. N.; and Jha, D. K. 2012. Plant growth-promoting rhizobacteria (PGPR): emergence in agriculture. World Journal of Microbiology and Biotechnology. 28(4):1327-1350.

Carreón, A. Y.; Sarabia, O. M.; Martínez, T. M. y Madrigal, P. R. 2013. Plantas, hongos micorrízicos y bacterias: su compleja red de interacciones Biológicas. Revista de La DES Ciencias Biológico Agropecuarias. Universidad Michoacana de San Nicolás de Hidalgo. 12(1):65-71.

David-Santoya, J. J. E.; Gómez-Álvarez, R.; Jarquín-Sánchez, A. y Villanueva-López, G. 2018. Caracterización de vermicompostas y su efecto en la germinación y crecimiento de Capsicum chinense Jacquin. Ecosistemas y Recursos Agropecuarios. 5(14):181-190.

Glick, B. R. 2012. Plant growth-promoting bacteria: Mechanisms and Applications. Scientifica. 2012 (963401). 1-15.

González-Solano, K. D.; Rodríguez-Mendoza, M. N.; Sánchez-Escudero, J.; Trejo-Téllez, L. I. y García-Cué, J. L. 2014. Uso de té de vermicompost en la producción de hortalizas de hoja. Agroproductividad. 7(6):17-22.

González, S. K.; Rodríguez, M. M.; Trejo-Téllez, L.; García, C. J. y Sánchez, E. J. 2013. Efluente y té de vermicompost en la producción de hortalizas de hoja en sistema NFT. Interciencia. 38(12):863-869.

Hunt, R. 2017. Growth analysis, individual plants. Editor(s): Brian Thomas, Brian G. Murray, Denis J. Murphy. Encyclopedia of Applied Plant Sciences (Second Edition), Elsevier. Academic Press. 421-429 pp.

Jones Jr, J. B. 2014. Complete guide for growing plants hydroponically. CRC Press Press Taylor and Francis. Fl., USA. 208 p.

López-Baltazar, J.; Méndez-Matías, A.; Pliego-Marín, L.; Aragón-Robles, E. y Robles-Martínez, M. L. 2013. Evaluación agronómica de sustratos en plántulas de chile 'onza' (Capsicum annuиm) en invernadero. Rev. Mex. Cienc. Agríc. 4(especial):1139-1150.

Luna, M. L.; Martínez, P. R. A.; Hernández, I. M.; Arvizu, M. S. M. y Pachec, A. J. R. 2013. Caracterización de rizobacterias aisladas de tomate y su efecto en el crecimiento de tomate y pimiento. Revista Fitotecnia Mexicana. 36(1):63-69.

Marschner, P. 2012. Mineral nutrition of higher plants. $3^{\text {rd }}$ edition. London: Elsevier. 561 p.

Mohamed, I.; Eid, K. E.; Abbas, M. H. H.; Salem, A. A.; Ahmed, N.; Ali, A.; Shah, G. M. and Fang, C. 2019. Use of plant growth promoting rhizobacteria (PGPR) and mycorrhizae to improve the growth and nutrient utilization of common bean in a soil infected with white rot fungi. Ecotoxicology and Environmental Safety. 171(1):539-548.

Moreno, R. A.; Carda, M. V.; Reyes, C. J. L.; Vásquez, A. J. y Can, R. P. 2018. Rizobacterias promotoras del crecimiento vegetal: una alternativa de biofertilización para la agricultura sustentable. Revista Colombiana de Biotecnología. 20(1):68-83. 
Natarajan A.; Velusamy J.; Krishna K. and Nooruddin T. 2012. Isolation and characterization of plant growth promoting endophytic bacteria and their effect on tomato (Lycopersicon esculentum) and chilli (Capsicum annuum) seedling growth Natarajan. Ann Microbiol 62(2): 805-810.

Ortiz-Texón, J. A.; Delgadillo-Martínez, J.; Rodríguez-Mendoza, M. N. y Calderón-Zavala, G. 2016. Inoculación bacteriana en el crecimiento y calidad del fruto de cinco variedades de fresa en suelos con pH contrastante. Terra Latinoamericana. 34(2):177-185.

Parra-Terraza, S. 2016. Relaciones $\mathrm{NO}_{3}{ }^{-}$/aniones y $\mathrm{K}+$ /cationes en la solución nutritiva para el crecimiento de plántulas de tomate. Rev. Mex. Cienc. Agríc. 7(7):1527-1538.

Pérez, U.; Ramírez, M.; Zapata, Y. y Córdoba, J. 2015. Efecto de la inoculación simple y combinada con hongos formadores de micorriza arbuscular (HFMA) y rizobacterias promotoras de crecimiento vegetal (BPCV) en plántulas micropropagadas de mora (Rubus glaucus L.). Corpoica Ciencia y Tecnología Agropecuaria. 16(1):95-103.

Quiroz-Sarmiento, V. F.; Almaraz-Suarez J. J.; Sánchez-Viveros G.; Argumedo-Delira R. y González-Mancilla A. 2019. Biofertilizantes de rizobacterias en crecimiento de plántulas de chile poblano. Rev. Mex. Cienc. Agric.10(8):1733-1745.

Richmond, F. 2010. Evaluación de distintas materias primas para la producción de almacigo de tomate. Agronomía Costarricense. 34(1):85-91.

Riveros-Rosas, H.; Julián-Sánchez, A.; Moreno-Hagelsieb, G. and Muñoz-Clares, R. A. 2019. Aldehyde dehydrogenase diversity in bacteria of the Pseudomonas genus. ChemicoBiological Interactions. 304(1):83-87.

Rojas, A.; Holguin, G.; Glick, B. R. y Bashan, Y. 2001. Synergism between Phyllobacterium sp. (N2-fixer) and Bacillus licheniformis (P-solubilizer), both from a semiarid mangrove rhizosphere. FEMS Microbiology Ecology. 35(2):181-187.

Salusso, F.; Plevich, J. O.; Delgado, A. R. S.; Grosso, L. y Ramos, D. 2015. Calidad de plántulas de lechuga en diferentes volúmenes de celdas y su influencia en el rendimiento. Revista Engenhariana Agricultura-Reveng. 23(6):575-583.

Santos, N. M. de S. S.; Queiroz, M. A. Á.; de Araújo, G. G. L.; Costa, S. A. P.; de Albuquerque, Í. R. R.; Moura, J. H. A. y Manera, D. B. 2014. Salinidade na água de beber de ovinos e uso dos dejetos em cultivo de plântulas de milho. Ciência Rural. 44(3):531-537.

Sapre, S.; Gontia M. I. \& Tiwari, S. 2018. Klebsiella sp. confers enhanced tolerance to salinity and plant growth promotion in oat seedlings (Avena sativa), Microbiological Research. 206(1):25-32.

Sarduy, D. M.; Díaz, A. I.; Castellanos, G. L.; Soto, O. R. y Pérez, R. Y. 2016. Sustratos y soluciones nutritivas para la obtención de plántulas de pimiento y su influencia en la producción en cultivos protegido. Centro Agrícola. 43(4):42-48.

SAS Institute Inc. 2014. Statistical Analysis System (SAS), version 9.4. SAS Institute Inc Cary NC., USA.

Shabayev, V. P. 2012. Mineral nutrition of plants inoculated with plant growth-promoting rhizobacteria of Pseudomonas genus. Biology Bulletin Reviews. 2(6):487-499.

Souri, M. K. and Sooraki, F. Y. 2019. Benefits of organic fertilizers spray on growth quality of chili pepper seedlings under cool temperature. Journal of Plant Nutrition. 42(6):650-656.

Steiner, A. A. 1984. The universal nutrient solution. In: Proceedings of the $6^{\text {th. }}$ International Congress on Soilless Culture. ISOSC. Wageningen, The Netherlands. 633-649 pp.

Syed, S. and Tollamadugu, N. P. 2019. Role of plant growth-promoting microorganisms as a tool for environmental sustainability. In Recent Developments in Applied Microbiology and Biochemistry. Academic Press. 209-222 pp. 
Tortosa, M. G. 2017. Té de compost (y de vermicompost). Ae Agroecología y ganadería ecológicas. 29-57 pp.

Vazallo, S. N.; Ramírez, L. T.; Carranza, L. T.; García, B. Z. y Bernilla, B. S. 2013. Efecto de la inoculación de Rhizobium etli y Trichoderma viride sobre el crecimiento aéreo y radicular de Capsicum annum var. longum. Revista Rebiolest. 1(1):11-21.

Vidigal, D. S.; Dias, D. C. F. S.; Dias, L. A. S.; Finger, F. L. 2011. Changes in seed quality during fruit maturation of sweet pepper. Scientia Agricola. 68(5):535-539.

Villar, R.; Ruiz-Robleto, J.; Quero, J. L.; Poorter, H.; Valladares, F. y Marañón, T. 2004. Tasas de crecimiento en especies leñosas: aspectos funcionales e implicaciones ecológicas. Ecología del bosque mediterráneo en un mundo cambiante, en: Valladares, F. Ecología del bosque mediterráneo en un mundo cambiante. Ministerio de Medio Ambiente, EGRAF, S. A. Madrid. 191-227 pp.

Widnyana, I. K. and Javandira, C. 2016. Activities Pseudomonas spp. and Bacillus sp. to stimulate germination and seedling growth of tomato plants. Agriculture and Agricultural Science Procedia. 9(1):419-423. 